\title{
Prevalence of Urinary Tract Conditions and Factors Associated with Urolithiasis in Domestic Cats in Nairobi, Kenya
}

\author{
Wilson K Kimani ${ }^{*}$, J Nguhiu-Mwangi, John D Mande and Susan W Mbugua \\ Department of Clinical Studies, University of Nairobi, P.O Box 29053-00625, Nairobi, Kenya \\ *Corresponding author: wkkimani@uonbi.ac.ke
}

\begin{abstract}
\begin{tabular}{llll}
\hline Article History: 20-164 Received: 30-Jul-20 & Revised: 11-Oct-20 & Accepted: 19-Oct-20
\end{tabular}
\section{ABSTRACT}

This was a retrospective study that covered a 10-year period from January 2009 to December 2018. The study had three aims which were to determine prevalence, clinical manifestations and factors associated with urolithiasis in domestic cats in Nairobi County, Kenya. It also considered prevalence of other urinary tract conditions that occurred in domestic cats in the same county. Clinical data of all cases of cats were collected from 5 purposively selected veterinary clinics. Specific data was retrieved, which included breed, sex, age, weight, neuter history, and clinical findings. Univariate and multivariate analysis was done to determine factors associated with urolithiasis. The total number of domestic cat cases in the 10 -year period was 4,404. A total of 104 cases had urinary tract conditions, of which 28 had urolithiasis, thus making general overall prevalence of urinary tract conditions to be $2.4 \%$ and prevalence of urolithiasis $0.6 \%$. Among cases with urinary tract conditions, prevalence of urolithiasis was $26.9 \%$. Definitive diagnosis of causes of urinary tract disease in cats was recorded in 75 cases. Urolithiasis was the major cause $37.3 \%$ followed by idiopathic feline lower urinary tract diseases and idiopathic cystitis both at $22.7 \%$. The results showed that history of dysuria, distended urinary bladder and body weight were significantly associated with urolithiasis in domestic cats. This current study concluded that prevalence of urolithiasis in Nairobi County, Kenya was low, but among cases with urinary tract conditions, it had the highest prevalence. These findings were different from similar literature where idiopathic cystitis is reported to be the major cause of urinary tract disease in cats. The main clinical symptoms of cats suffering from urolithiasis were dysuria, hematuria, stranguria, distended urinary bladder and painful abdomen.
\end{abstract}

Key words: Cats, Urolithiasis, Urinary tract diseases.

\section{INTRODUCTION}

There is a wide range of urinary tract conditions in domestic cats, including urolithiasis, feline urologic syndrome (FUS), bacterial infection, cystitis, idiopathic cystitis, urethral obstruction and neoplasia (Mateescu et al. 2012). Urolithiasis accounts for $22 \%$ of the cats suffering from feline lower urinary tract disease (Gerber et al. 2005) and $56.06 \%$ of cats with urinary tract diseases (Mateescu et al. 2012). Occurrence of urolithiasis is estimated to be approximately 15 to $21 \%$ in cats with clinical signs of lower urinary tract disease (Hunprasit et al. 2019).

Urolithiasis is the occurrence and the effects of urinary calculi in the urinary tract and is one of the common causes of clinical signs linked to feline urinary tract (Lulich et al. 2011). Uroliths commonly occur in the urinary bladder and the urethra. They are composed of small amounts of organic matrix (mucoid material) and large amounts of crystalline material, which are either organic or inorganic crystalloids. In cats, four types of uroliths occur, which include struvite (magnesium ammonium phosphate), calcium oxalates, calcium phosphate and urate. Uroliths can also be composed of a mixture of all these minerals (Norsworthy 2011).

Urolithiasis is reported to occur more frequently in male than female cats (Hesse et al. 2012; Hunprasit et al. 2019). Castrated cats contribute $85 \%$ of the cases of uroliths analyzed and have 8.3 times greater risk of developing uroliths than intact male cats (Picavet et al. 2007). Two studies found neutered cats with higher percentage of cases of urolithiasis than intact cats (Picavet et al. 2007, Hesse et al. 2012). In contrast, a higher percentage of cases of urolithiasis was found in intact than neutered female cats (Hunprasit et al. 2019).

According to Norsworthy (2011), diagnosis of urolithiasis is dependent on clinical signs of hematuria,

Cite This Article as: Kimani WK, Nguhiu-Mwangi J, Mande JD and Mbugua SW, 2021. Prevalence of urinary tract conditions and factors associated with urolithiasis in domestic cats in Nairobi. International Journal of Veterinary Science 10(3): 196-201. https://doi.org/10.47278/journal.ijvs/2021.042 
dysuria, pollakiuria, periuria or symptoms of urethral obstruction; while confirmation is by radiography or ultrasonography. Palpation is done during clinical examination but elicits pain. Treatment of urolithiasis includes surgical removal of the uroliths, retrograde urohydropropulsion, dietary or medical dissolution of the uroliths, and antibiotic therapy for bacteria-induced uroliths (Norsworthy 2011). There is no literature on prevalence and factors associated with urolithiasis in domestic cats in Kenya. Hence the reason for this publication which will facilitate veterinary practitioners in diagnosis, treatment, and judging of prognosis for domestic cats with urinary tract conditions.

\section{MATERIALS AND METHODS}

\section{Study Design}

This was a retrospective study of cases of urolithiasis in domestic cats presented to Veterinary Clinics in Nairobi County, Kenya over a 10-year period from January 2009 to December 2018. The five Veterinary Clinics were purposively selected based on the ease of acceptance by the clinic owners to allow access to clinic records. Many clinic owners would decline access to the records for thorough scrutiny.

\section{Geographical Study Area}

The study was carried out in Nairobi County, Kenya. Nairobi County is one of the 47 Counties of Kenya. It has a population of over 4 million people and is located $1^{\circ} .2921 \mathrm{~S}, 36.8219 \mathrm{E}$. The County has an average temperature and a mean annual rainfall of $19^{\circ} \mathrm{C}$ and 869 $\mathrm{mm}$ respectively.

People in this county keep various companion animals including dogs, cats and horses, which require veterinary health care. Small animal practice is common in this county, evidenced by numerous small animal veterinary clinics.

\section{Data Collection}

In each of the veterinary clinics, all the cases of cats presented for treatment from January 2009 to December 2018; with exception of those cases presented for routine vaccinations and deworming, were retrieved from the clinic archived case records. These were further scrutinized to identify specific cases of urolithiasis. For each case with urolithiasis, specific data was retrieved, which included breed, sex, age, weight, neuter history and presenting clinical symptoms.

\section{Data Management and Analysis}

Data was entered into Microsoft Office Excel 2013 (Microsoft Inc., Sacramento, California, USA). It was verified and validated as correct entries according to the data collection sheets. It was imported into Stata 15 (StataCorp LLC, College station, Texas, USA) for analysis. Descriptive statistics were analyzed. Proportions were determined for categorical variables i.e. sex, breed and neuter history. The range, means, standard deviations and medians were determined for continuous variables i.e. weight and age.

Univariable analysis using simple logistic regression was performed to determine unconditional associations with the occurrence of urolithiasis. Variables with a $\mathrm{P} \leq 0.25$ were selected for multivariable analysis. Multivariable logistic regression was performed to determine actual factors that are most likely to be associated with the occurrence of urolithiasis and eliminate those that are most unlikely. The final models were built using backwardstepwise elimination of the most unlikely variables, leaving only variables which had $\mathrm{P} \leq 0.05$. To evaluate the final multivariate model, a goodness-of-fit test was done and an area under the receiver operating characteristic curve (ROC) was determined.

The proportion of urolithiasis was calculated from the total number of cases in the 5 clinics as well as for each individual clinic as follows:

$$
\begin{aligned}
& \text { Overall prevalence of urolithiasis }=\frac{\text { Total No. of cases with urolithiasis }}{\text { Total No. of cat cases presented }} \\
& \text { Percentage of urolithiasis for each clinic }=\frac{\text { No. with urolithiasis in the clinic }}{\text { Total No. of cases presented }} \times 100
\end{aligned}
$$

Percentage of clinical signs of urolithiasis was also calculated as follows:

Percentage of clinical signs $=\frac{\text { Total No. of cases with the clinical sign }}{\text { Total No. with urolithiasis }} \times 100$

\section{RESULTS}

\section{Descriptive Statistics}

The overall total cases of domestic cats presented in the five clinics in the 10 -year period was 4,404 , which makes the prevalence of urolithiasis in Nairobi County to be $0.6 \%$ (Table 1). The total number of recorded cases of cats that suffered from various urinary tract conditions was 104 . The prevalence of urolithiasis among urinary tract conditions was therefore $26.9 \%$. Gender of the cat was indicated in 26 cases among which, $76.9 \%$ male cats had urolithiasis and female cats at $23.1 \%$. Neuter history of the cats with urolithiasis was indicated in 23 cases. Among these, $60.9 \%$ were neutered and $39.1 \%$ were sexually intact.

The breeds of the cat affected by urolithiasis were available in $89.3 \%(n=25)$ cases. The breed mostly affected with urolithiasis was domestic shorthair at $84.0 \%$, followed by Persian at $8.0 \%$, domestic longhair and Siamese each at $4.0 \%$. The mean age and weight of cats diagnosed with urolithiasis was 6.19 years and $4.97 \mathrm{~kg}$ respectively, with $78.6 \%$ of the cats with urolithiasis weighing $>4.50 \mathrm{~kg}$.

\section{Clinical History and Symptoms}

The clinical histories found in the case records had been obtained through cat owners narrating them to the attending veterinarians. These histories were available in 27 cases of those with urolithiasis. The histories included dysuria (37.0\%), hematuria $(29.6 \%)$ and stranguria $(22.2 \%)$ (Table 2). Information on clinical examination findings in the case records was available only in $85.7 \%$ of the cats with urolithiasis. Distended urinary bladder had the highest frequency at $54.2 \%$. Others with low frequency included painful abdomen at $16.7 \%$ and hematuria at $8.3 \%$ (Table 3).

The cases of urolithiasis $(n=28)$ that were examined by ultrasonography or radiography were $78.6 \%$. Among these $(n=22)$, distended urinary bladder was found in $63.6 \%$ and uroliths were identified in $13.6 \%$ of the cases (Table 4 ). 
Int J Vet Sci, 2021, 10(3): 196-201.

Table 1: Overall number of cat cases and those with urinary tract conditions presented in the five small animal clinics in Nairobi County, Kenya from January 2009 to December 2018

\begin{tabular}{lcccc}
\hline Clinics & $\begin{array}{c}\text { Overall number of } \\
\text { cat cases }\end{array}$ & $\begin{array}{c}\text { Number with urinary tract } \\
\text { conditions }\end{array}$ & $\begin{array}{c}\text { Percentage with urinary tract } \\
\text { conditions }(\mathrm{n}=104)\end{array}$ & $\begin{array}{c}\text { Percentage with urinary tract } \\
\text { conditions per clinic }\end{array}$ \\
\hline CL 2 & 1534 & 42 & 40.4 & 2.7 \\
CL 1 & 1088 & 25 & 24.0 & 2.3 \\
CL 3 & 1224 & 16 & 15.4 & 1.3 \\
CL 4 & 153 & 14 & 13.5 & 9.2 \\
CL 5 & 405 & 7 & 6.7 & 1.7 \\
Total & 4404 & 104 & 100 & (Overall 2.4\%) \\
\hline
\end{tabular}

Table 2: Frequencies of various clinical history given by the cat owners during presentation of cats $(n=27)$ with urolithiasis to the veterinary clinics from January 2009 to December 2018

\begin{tabular}{lcc}
\hline History & Number & Percentage \\
\hline Dysuria & 10 & 37.0 \\
Hematuria & 8 & 29.6 \\
Stranguria & 6 & 22.2 \\
Urinary incontinence & 4 & 14.8 \\
Non-specific finding & 3 & 11.1 \\
Polyuria & 1 & 3.7 \\
\hline
\end{tabular}

Table 3: The frequencies of commonly encountered clinical findings in cats $(n=24)$ that were presented to the Veterinary Clinics with urolithiasis from January 2009 to December 2018

\begin{tabular}{lcc}
\hline Clinical findings & Number & Percentage \\
\hline Distended urinary bladder & 13 & 54.2 \\
Painful abdomen & 4 & 16.7 \\
Hematuria & 2 & 8.3 \\
\hline
\end{tabular}

Table 4: The findings in the cases of cats with urolithiasis $(n=22)$ that underwent diagnostic imaging in the five designated veterinary clinics in Nairobi County, Kenya from January 2009 to December 2018

\begin{tabular}{lcc}
\hline Findings through imaging & Number & Percentage \\
\hline Distended urinary bladder & 14 & 63.6 \\
No abnormality & 4 & 18.2 \\
Uroliths & 3 & 13.6 \\
Nonspecific finding & 1 & 4.6 \\
\hline Total & 22 & 100 \\
\hline
\end{tabular}

Table 5: The frequencies of various diagnoses made in domestic cats presented with symptoms of urinary tract conditions in the five designated veterinary clinics in Nairobi County, Kenya from January 2009 to December 2018 clinical records $(n=75)$

\begin{tabular}{lcc}
\hline Diagnoses & $\begin{array}{c}\text { *Number } \\
\text { of cases }\end{array}$ & *Percentage \\
\hline Urolithiasis & 28 & 37.3 \\
Idiopathic Feline urologic syndrome & 17 & 22.7 \\
Idiopathic cystitis & 17 & 22.7 \\
Urinary tract infection & 16 & 21.3 \\
Renal failure & 8 & 10.7 \\
Trauma & 3 & 4.0 \\
Streptomycin toxicity & 1 & 1.3 \\
Mycoplasmosis & 1 & 1.3 \\
\hline
\end{tabular}

*Some $(28 \%(21 / 75)$ of the cases had more than one tentative diagnosis made after examination, hence total number would exceed the actual number and the total percentage would exceed $100 \%$.

\section{Specific Diagnoses of Urinary Tract Conditions}

Specific diagnoses of urinary tract conditions were indicated in the records of only $72.1 \%(75 / 104)$ of the cases. The highest among the conditions being urolithiasis $(n=75)$ with a frequency of $37.3 \%$ and the lowest being trauma at $4.0 \%$. No definitive diagnosis was recorded in $22.7 \%$ of the cases, instead the cats were recorded as suffering from idiopathic feline urologic syndrome.
Table 6: The number of domestic cats presented with urolithiasis to the five designated veterinary clinics in Nairobi County, Kenya from January 2009 to December $2018(n=28)$

\begin{tabular}{lcc}
\hline Clinic & Number of cases of urolithiasis & Percentage \\
\hline CL2 & 14 & 50.0 \\
CL1 & 5 & 17.9 \\
CL3 & 4 & 14.3 \\
CL4 & 3 & 10.7 \\
CL5 & 2 & 7.1 \\
Total & 28 & 100 \\
\hline
\end{tabular}

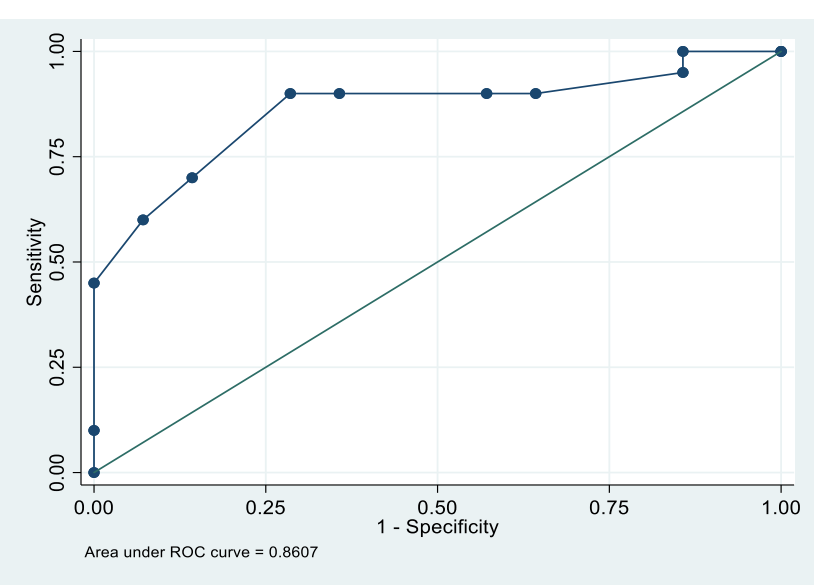

Fig. 1: Receiver operator characteristic curve describing the predictive ability of the multivariate analysis model for urolithiasis in domestic cats. This output shows that a cat suffering from urolithiasis is presented having dysuria, distended urinary bladder and increased weight.

The frequencies of the rest of the diagnoses of urinary tract conditions are presented in Table 5. The distribution of urolithiasis cases in the five designated veterinary clinics in Nairobi County are shown in Table 6.

\section{Factors Associated with the Occurrence of Urolithiasis}

Factors that were found to be significantly associated with urolithiasis included male gender $(\mathrm{P}=0.06)$, increase in weight $(\mathrm{P}=0.01)$, a history of dysuria, stranguria $(\mathrm{P}=0.12$ and $\mathrm{P}=0.07$, respectively) and clinical examination findings of hematuria, distended urinary bladder and painful abdomen $(\mathrm{P}=0.06, \mathrm{P}=0.007$ and $\mathrm{P}=0.09)$, respectively (Table 7).

The results showed that history of dysuria $(O R=0.10$; $\mathrm{CI}=0.01$ to $1.17 ; \mathrm{P}=0.066)$, distended urinary bladder $(\mathrm{OR}=20.79 ; \mathrm{CI}=2.32-186.22 ; \mathrm{P}=0.007)$ and body weight $(\mathrm{OR}=16.45 ; \mathrm{CI}=1.38-196.68 ; \mathrm{P}=0.027)$ were significantly associated with urolithiasis in domestic cats. The area under Receiver Operator Characteristic (ROC) curve was 0.8607. This means that a domestic cat is more likely to be suffering from urolithiasis when presented having dysuria, distended urinary bladder and have increased body weight (Fig. 1). 
Int J Vet Sci, 2021, 10(3): 196-201.

Table 7: Results of univariate analysis showing various factors associated with urolithiasis in domestic cats in Nairobi County, Kenya.

\begin{tabular}{|c|c|c|c|c|}
\hline Variable & Category & Proportion with urinary tract conditions $(\%)$ & Proportion with Urolithiasis (\%) & $\mathrm{P}$ value \\
\hline \multirow[t]{2}{*}{ Breed of cats } & $\mathrm{DSH}$ & $68(78.2)$ & $21(84.0)$ & 0.463 \\
\hline & Others & $19(21.8)$ & $4(16.0)$ & \\
\hline \multirow[t]{5}{*}{ Veterinary clinics } & CL1 & $25(24.0)$ & $5(17.9)$ & 0.844 \\
\hline & CL2 & $42(40.4)$ & $14(50.0)$ & 0.550 \\
\hline & CL3 & $16(15.4)$ & $4(14.3)$ & 0.375 \\
\hline & CL4 & $14(13.5)$ & $3(10.7)$ & 0.824 \\
\hline & CL5 & $7(6.7)$ & $2(7.1)$ & 0.926 \\
\hline \multirow[t]{2}{*}{ Sex of the cat } & Female & $34(35.4)$ & $6(23.1)$ & $0.056^{*}$ \\
\hline & Male & $62(64.6)$ & $20(76.9)$ & \\
\hline \multirow[t]{2}{*}{ Weight of the cat } & $<=4.50$ & $42(40.4)$ & $6(21.4)$ & $0.011 *$ \\
\hline & $>4.50$ & $62(59.6)$ & $22(78.6)$ & \\
\hline \multirow[t]{2}{*}{ Neuter history } & Intact & $50(61.7)$ & $14(60.9)$ & 0.707 \\
\hline & Neutered & $31(38.3)$ & $9(39.1)$ & \\
\hline \multirow[t]{2}{*}{ History of dysuria } & No & $76(76.8)$ & $17(63.0)$ & $0.117 *$ \\
\hline & Yes & $23(23.2)$ & $10(37.0)$ & \\
\hline \multirow[t]{2}{*}{ History of urinary incontinence } & No & $82(84.5)$ & $4(15.4)$ & 0.629 \\
\hline & Yes & $15(15.5)$ & $22(84.6)$ & \\
\hline \multirow[t]{2}{*}{ History of hematuria } & No & $59(56.6)$ & $19(70.4)$ & 0.606 \\
\hline & Yes & $40(40.4)$ & $8(29.6)$ & \\
\hline \multirow[t]{2}{*}{ History of polyuria } & No & $93(93.9)$ & $26(96.3)$ & 0.417 \\
\hline & Yes & $6(6.1)$ & $1(3.7)$ & \\
\hline \multirow[t]{2}{*}{ History of stranguria } & No & $83(83.8)$ & $21(77.8)$ & $0.067 *$ \\
\hline & Yes & $16(16.2)$ & $6(22.2)$ & \\
\hline \multirow[t]{2}{*}{ Non-specific clinical history } & No & $75(75.8)$ & $24(88.9)$ & $0.031 *$ \\
\hline & Yes & $24(24.2)$ & $3(11.1)$ & \\
\hline \multirow{2}{*}{$\begin{array}{l}\text { Examination finding of } \\
\text { hematuria }\end{array}$} & No & $61(78.2)$ & $22(91.7)$ & $0.055^{*}$ \\
\hline & Yes & $17(21.8)$ & $2(8.3)$ & \\
\hline \multirow{2}{*}{$\begin{array}{l}\text { Examination finding of } \\
\text { distended urinary bladder }\end{array}$} & No & $50(64.9)$ & $11(45.8)$ & $0.007 *$ \\
\hline & Yes & $27(35.1)$ & $13(54.2)$ & \\
\hline \multirow{2}{*}{$\begin{array}{l}\text { Examination finding of painful } \\
\text { abdomen }\end{array}$} & No & $73(93.6)$ & $20(83.3)$ & $0.091 *$ \\
\hline & Yes & $5(6.4)$ & $4(16.7)$ & \\
\hline \multirow{2}{*}{$\begin{array}{l}\text { Imaging finding as distended } \\
\text { urinary bladder }\end{array}$} & No & $22(50.0)$ & $6(30.0)$ & $0.021 *$ \\
\hline & Yes & $22(50.0)$ & $14(70.0)$ & \\
\hline \multirow{2}{*}{ Normal imaging findings } & No & $27(67.5)$ & $14(77.8)$ & $0.218^{*}$ \\
\hline & Yes & $13(32.5)$ & 422.2() & \\
\hline \multirow[t]{2}{*}{ Urinalysis -Erythrocytes in urine } & No & $4(30.8)$ & $1(16.7)$ & 0.322 \\
\hline & Yes & $9(69.2)$ & $5(83.3)$ & \\
\hline \multirow[t]{2}{*}{ Urinalysis - leucocytes } & No & $5(38.5)$ & $3(50.0)$ & 0.888 \\
\hline & Yes & $7(53.9)$ & $3(50.0)$ & \\
\hline \multirow[t]{2}{*}{ Diagnosis of FUS } & No & $59(77.6)$ & $25(89.3)$ & $0.073^{*}$ \\
\hline & Yes & $17(22.4)$ & $3(10.7)$ & \\
\hline \multirow{2}{*}{$\begin{array}{l}\text { Diagnosis of urinary tract } \\
\text { infection }\end{array}$} & No & $59(78.7)$ & $26(96.3)$ & $0.020 *$ \\
\hline & Yes & $16(21.3)$ & $1(3.7)$ & \\
\hline
\end{tabular}

Key: *represent variables with $\mathrm{P}<0.25$.

Table 8: Multivariate analysis of variables associated with urolithiasis in domestic cats in domestic cats in Nairobi County, Kenya

\begin{tabular}{lcccc}
\hline Variable & OR & \multicolumn{3}{c}{ 95\% CI value } \\
\cline { 3 - 5 } & & LCL & UCL & 0.027 \\
Weight of the cat & 16.45 & 1.38 & 196.68 & 0.066 \\
History of dysuria & 0.10 & 0.01 & 1.17 & 0.036 \\
Non-specific clinical history & 0.06 & 0.04 & 0.83 & 0.007 \\
Imaging finding as distended urinary bladder & 20.79 & 2.32 & 186.22 & 0.22 \\
\hline
\end{tabular}

\section{DISCUSSION}

It has been suggested that old cats are the most likely to have urinary disorders (Yamazaki et al. 2016). The average reported age range of cats suffering from urolithiasis is 5.0 to 7.2 years (Gerber et al. 2005; Hesse et al. 2012; Hunprasit et al. 2019). This is similar to the findings from the current study where cats affected by urolithiasis had a mean age of 6.19 years. Body weight is one of the risk factors for occurrence of urinary tract diseases in cats (Lew-Kojrys et al. 2016). Obese cats have a higher susceptibility for lower urinary tract disease than lean cats (Gerber 2008; Woolf 2012). This is due to associating obesity with increase in food intake, fat storage in the body and mineral excretion in urine (da Rosa Gomes et al. 2018). In humans, large body size has been incriminated as a predisposing factor for increased excretion of uric acid and oxalates in urine, which enhances the likelihood of calcium oxalate urolith formation (Taylor et al. 2005). Similarly, in one study, cats with urolithiasis were recorded as having an average weight $\geq 5.0 \mathrm{~kg}$ (Gerber et al. 2005; Hesse et al. 2012). This may explain the reason why in the current study urolithiasis in domestic cats was found to be associated with large body with most cats weighing $>4.50 \mathrm{~kg}$.

It has been observed that the clinical manifestations of urolithiasis in cats vary with the quantity, size and location 
of the uroliths (Grauer 2015). Hence the clinical signs are not specific, but those that are more consistent include hematuria, stranguria, dysuria and periuria (da Rosa Gomes et al. 2018). Nephroliths are usually asymptomatic but might be associated with macroscopic or microscopic hematuria; while ureteroliths may also be asymptomatic or associated with abdominal pain and low appetite (Grauer 2015). Cats with cystoliths might present with signs of pollakiuria, dysuria, stranguria and hematuria (Syme 2012). Urethral uroliths are common cause of partial or complete urethral blockage in male cats, leading to anuria, hematuria, dysuria or stranguria (Grauer 2015). Dorsch et al. (2014) reported hematuria as the most frequent clinical symptom in urolithiasis, followed by urethral obstruction and stranguria. In the current study, dysuria was the most frequently recorded clinical sign in cats that had urolithiasis.

The findings that male cats were more frequently affected by urolithiasis than females, compare closely with similar observations in previous studies (Hesse and Sanders, 1985; Gerber et al. 2005; Hesse et al. 2012; Hunprasit et al. 2019). Other studies have also concluded that male cats are more likely to suffer from various urinary tract conditions especially urethral obstructions than females (Mateescu et al. 2012; Yamazaki et al. 2016).

The study found that neutered cats were more likely to be affected by urolithiasis than sexually intact cats, which corroborates findings by previous researchers (Hesse et al. 2012). Neutering predisposes cats to drinking less water (Eugênio et al. 2009), which increases the probability of urolith development (Jones et al. 1997). It has been reported by Hunprasit et al. (2019) that urolithiasis was more in neutered male cats but was high in intact female cats. In both sexes, neutering is thought to be one of the predisposing factors for the development of feline lower urinary tract diseases (FLUTD), due to its association with suppression of urethral growth, weight gain induction and inactivity (da Rosa Gomes et al. 2018). Castration in cats may be associated with sedentary lifestyle and obesity, which predisposes cats to urolithiasis (da Rosa Gomes et al. 2018). Other factors associated with urolithiasis in cats that were not in the case records of the current study, includes diet, climate, infections, use of toxic and teratogenic agents, water and food source (da Rosa Gomes et al. 2018). This requires further studies so that the aforementioned predisposing factors can be investigated to enable proper and effective treatment and prevention of urolithiasis.

In this current study, domestic shorthair breed of cat was the most affected breed by urolithiasis followed by Persian, which may probably be due to preference for these breeds by most Nairobi County residents. However, this is similar to most of the past studies (Gerber et al. 2005; Houston and Moore, 2010; Hunprasit et al. 2019). In a study on uroliths submissions to the Canadian Veterinary Urolith Center, most submissions were from domestic shorthair, median hair, and longhair cats (Houston et al. 2016). Contrary to these results, Hesse et al. (2012) found that European shorthair breed was the most commonly affected breed by urolithiasis $(64.3 \%)$ followed by Persian breed $(15.2 \%)$. This could be due to the breed being endemic in the countries where uroliths were submitted for analysis. The uroliths were submitted largely from
Germany and partially from other European countries, which included Netherlands, Austria, Switzerland, Italy and Finland.

In the current study, the observation of urolithiasis as the major cause of urinary tract disease in cats followed by idiopathic FLUTD and idiopathic cystitis, contradicts previous reports. Previous reports indicate idiopathic cystitis as the more frequent cause of lower urinary tract disease in cats (Hostutler et al. 2005; Forrester 2007; Mateescu et al. 2012; Pusoonthornthum et al. 2012; Dorsch et al. 2014), then followed by urolithiasis (Lew-Kojrys et al. 2016; da Rosa Gomes et al. 2018). Among cats with FLUTD, 10 to $20 \%$ had urinary calculi and urethral plugs (Zohaib et al. 2013).

Cats with FLUTD have similar clinical signs, hence the necessity for use of diagnostic methods such as diagnostic imaging and laboratory tests, which will confirm the diagnosis (Gerber et al. 2005). Diagnosis of causes of FLUTD can be achieved on elimination basis of identifiable causes of the disease, e.g. neoplasia and bacterial infection (Jones et al. 1997), as well as urolithiasis, tumors and anatomical defects (Lew-Kojrys et al. 2016).

Physical examination should be done keenly to include the entire urinary tract and supplement it with additional examinations (Mateescu et al. 2012). These additional diagnostic methods that can be employed to confirm diagnosis include ultrasonography, urine cultures, cystoscopy, contrast radiography (Lew-Kojrys et al. 2016) and urinary bladder biopsy (Bovens 2011). Urinalysis is of great importance to reveal the underlying changes in the body systems before initiating therapy (Bovens 2011; Gerber 2018). Cystotomy may be used to confirm feline idiopathic cystitis (FIC) and to exclude other causes of FLUTD (Adams 2013). It is therefore possible that failure to use imaging and laboratory analysis routinely in the clinics where retrospective data was collected may have contributed to the high frequency of idiopathic FLUTD in this study. Use of more effective diagnostic methods may probably have revealed different diagnoses other than FLUTD.

\section{Conclusion and Recommendation}

The study concludes that the prevalence of urolithiasis in domestic cats in Nairobi County and probably in Kenya is low, but comparatively, its frequency is higher than other urinary tract diseases. Prevalence of urolithiasis in domestic cats in Nairobi County is relatively high in male cats especially those that are castrated, in shorthair breed and in heavier cats. Dysuria, distended urinary bladder and increase in weight of a cat are factors found to be associated with urolithiasis in domestic cats in Nairobi, Kenya.

It is recommended that a study on the composition of common uroliths affecting domestic cats in Nairobi County be done to assist in guiding the best treatment and prevention methods. A more comprehensive prospective study of risk factors for urolithiasis in domestic cats may be useful for guiding preventative measures.

\section{Authors Contribution}

WK collected and analyzed the data. JN, JD and SW contributed to the design and implementation of the 
research work, analysis of results and writing of the manuscript.

\section{REFERENCES}

Adams LG, 2013. Feline Idiopathic Cystitis. The $38^{\text {th }}$ Congress of the World Small Animal Veterinary Association Proceedings Online (WSAVA 2013), Auckland, New Zealand, March 2013.

Bovens C, 2011. Feline Lower Urinary Tract Disease. A diagnostic approach. Feline update pp: 1-12. Autumn. Bristol University.

da Rosa Gomes V, Ariza PC, Borges NC, Schulz FJ and Fioravanti MCS, 2018. Risk factors associated with feline urolithiasis. Veterinary Research Communications 42: 8794. https://doi.org/10.1007/s11259-018-9710-8

Dorsch R, Remer C, Sauter-Louis C and Hartmann K, 2014. Feline lower urinary tract disease in a German cat population. Tieraerztliche Praxis Ausgabe K: Kleintiere/ Heimtiere 42: 231-239.

Eugênio FR, Sakamoto SS, Silva CM, Ferreira GTNM, Souza TFB, Laranjeira MG and Andrade AL, 2009. Retrospective study of the feline lower urinary tract disease's cases between 2002 and 2009 admitted at Unesp-Araçatuba veterinary hospital. World Small Animal Veterinary Association World Congress Proceedings, 2009.

Forrester SD, 2007. Management of feline lower urinary tract disease. Journal of Veterinary Internal Medicine 21: 45.

George CM and Grauer GF, 2016. Feline Urethral Obstruction: Diagnosis \& Management Today's Veterinary Practice 6: 36-46.

Gerber B, 2008. Feline Lower Urinary Tract Diseases (FLUTD). In: Proceeding of the International SCIVAC Congress, Emstek, International Veterinary Information Service, pp: 201-203.

Gerber B, Boretti FS, Kley S, Laluha P, Müller C, Sieber N, Unterer S, Wenger M, Flückiger M, Glaus T and Reusch CE, 2005. Evaluation of clinical signs and causes of lower urinary tract disease in European cats. Journal of Small Animal Practice 46: 571-577.

Grauer GF, 2015. Feline struvite \& calcium oxalate urolithiasis. Today's Veterinary Practice 5: 14-20.

Hesse A and Sanders G, 1985. A survey of urolithiasis in cats. Journal of Small Animal Practice 26: 465-476.

Hesse A, Orzekowsky H, Frenk M and Neiger R, 2012. Epidemiological data of urinary stones in cats between 1981 and 2008. Tierarztliche Praxis. Ausgabe K, Kleintiere/ Heimtiere 40: 95-101.

Hostutler RA, Chew DJ and DiBartola SP, 2005. Recent concepts in feline lower urinary tract disease. Veterinary Clinics of North America: Small Animal Practice 35: 47-170.
Houston DM, Moore AE, Favrin MG and Hoff B, 2003. Feline urethral plugs and bladder uroliths: a review of 5484 submissions 1998-2003. Canadian Veterinary Journal 44: 974-977.

Houston DM, Vanstone NP, Moore AE, Weese HE and Weese JS, 2016. Evaluation of 21,426 feline bladder urolith submissions to the Canadian Veterinary Urolith Centre (1998-2014). The Canadian Veterinary Journal 57: 196-201.

Hunprasit V, Pusoonthornthum P, Koehler L and Lulich JP, 2019. Epidemiologic evaluation of feline urolithiasis in Thailand from 2010 to 2017. Thai Journal of Veterinary Medicine 49: 101-105. http://dx.doi.org/10.1016/j.rvsc.2017.07.008

Jones BR, Sanson RL and Morris, RS, 1997. Elucidating the risk factors of feline lower urinary tract disease. New Zealand Veterinary Journal 45: 100-108. http://doi.org/10.1080/ 00480169.1997.36003

Lew-Kojrys S, Mikulska-Skupien E, Snarska A, Krystkiewicz W and Pomianowski A, 2016. Evaluation of clinical signs and causes of lower urinary tract disease in Polish cats. Veterinami Medicina 62: 386-393.

Lulich JP, Osborne CA, Albasan H, 2011. Canine and feline urolithiasis: diagnosis, treatment, and prevention, in: Bartges $\mathrm{J}$ and Polzin DJ (editors), Nephrology and Urology in Small Animals. $1^{\text {st }}$ Ed. Blackwell, pp: 687-706.

Mateescu C, Tudor N and Mateescu Romaniţa VC, 2012. Study concerning the urinary tract diseases in cats in the Dâmboviţa County. Veterinary Medicine Journal 58: 244-248.

Norsworthy GD, 2011. Urolithiasis, in: Crystal MA, Grace SF, Tilley MLP (eds), The feline Patient, $4^{\text {th }}$ Ed. Blackwells, pp: 538-542

Picavet P, Detilleux J, Verschuren S, Sparkes A, Lulich J, Osborne C and Diez M, 2007. Analysis of 4495 canine and feline uroliths in the Benelux. A retrospective study: 19942004. Journal of Animal Physiology and Animal Nutrition 91: 247-251.

Pusoonthornthum R, Pusoonthornthum P and Osborne CA, 2012. Risk factors for feline lower urinary tract diseases in Thailand. Thai Journal of Veterinary Medicine 42: 517-522.

Syme HM, 2012. Stones in cats and dogs: What can be learnt from them? Arab Journal of Urology 10: 230-239. https://doi.org/ 10.1016/j.aju.2012.06.006

Taylor EN, Stampfer MJ and Curhan GC, 2005. Obesity, weight gain, and the risk of kidney stones. Journal of American Medical Association 293: 455-462.

Woolf K, 2012. Feline lower urinary tract disease: predisposition, causes and nursing care. The Veterinary Nurse 3: 406-412.

Yamazaki M, Inoue M and Sugiura K, 2016. Association between age, breed and sex in relation to urinary disorders in insured cats in Japan during fiscal year 2012. Journal of Veterinary Medical Science 78: 1521-1524. https://dx.doi.org/10.1292 \%2Fjvms.16-0074.

Zohaib A, Taj Z, Sial AUR, Naeem MA and Saqlein M, 2013. Feline lower urinary tract disease-report of four cases. Pakistan Veterinary Journal 33: 131-132. 